\title{
O CORPO DE DEUS EM ESTADO CRÍTICO: UMA LEITURA DO CRISTIANISMO NA LÍRICA CAMONIANA E NOS POEMAS DE RUY BELO
}

\section{THE BODY OF GOD IN CRITICAL STATE: A READING OF CHRISTIANITY IN CAMÕES'S LYRIC AND RUY BELO'S POEMS}

Kigenes Simas ${ }^{1}$

\section{RESUMO}

O presente artigo é uma análise do modo como a hermenêutica histórica cristã e o modelo de corporeidade do cristianismo foram mobilizados na lírica de Camões e nos poemas de Ruy Belo. Nossa abordagem parte do problema da encarnação do Cristo e do vínculo à ressurreição enquanto elementos constitutivos da formulação cristã da temporalidade, tendo em vista a forma como Camões e Ruy Belo os pervertem em seus respectivos procedimentos poéticos. Acreditamos que o confronto dos dois poetas com esses aspectos do cristianismo produz formas poéticas de grande potencial crítico.

PALAVRAS-CHAVE: cristianismo; Camões; Ruy Belo; crise.

\section{ABSTRACT}

The present article is an analysis of the way Christian Historical Hermeneutics and the Christian model of corporeality were mobilized in Camões's poetry and Ruy Belo's poems. Our approach is based on the problem of the incarnation of Christ and its link to resurrection as constitutive elements of the Christian formulation of temporality, given the way in which Camões 
and Ruy Belo pervert them in their respective poetic procedures. We believe that the confrontation of the two poets with these aspects of Christianity produce poetic forms of great critical potential.

KEYWORDS: Christianity; Camões; Ruy Belo; crisis.

\section{INTRODUÇÃO}

Não se trata do mesmo cristianismo quando analisamos os procedimentos estéticos que um poeta do século XVI, Luís Vaz de Camões, e outro do século XX, Ruy Belo, produziram a partir da experiência cristã. No entanto, não devemos esquecer que, assim como a cultura cristã no Ocidente tem uma história, ela também produziu sua própria hermenêutica dos fatos históricos. Tal hermenêutica encontra-se, a uma só vez, próxima e distante de nossa forma de ler historicamente os acontecimentos. Próxima, na medida em que o cristianismo é a forma cultural majoritária no Ocidente, e distante, uma vez que, ao menos desde a passagem do século XVIII ao XIX, a exegese cristã da história foi contraposta institucionalmente à razão de estado, enquanto regime racional, calculado e projetivo do tempo. Como se sabe, no cerne dessa tensão estava a crise do paradigma escatológico do tempo, isto é, da espera diferida pelo fim do mundo, base da historiografia cristã, e as perspectivas abertas pela noção de progresso histórico, cuja emergência, como examina Reinhart Koselleck (2006), em seu livro clássico Futuro Passado, foi correlativa à formação do estado moderno. Para Koselleck, a noção de progresso, formalizada pelas filosofias da história do século XVIII, foi uma tentativa de converter a crise de legitimidade do antigo regime em um programa político de condução racional dos conflitos. Contudo, não é no nível dessa ruptura que nossa análise tentará se manter, ainda que possamos recorrer a ela. Por ora, basta dizermos que $o$ que queremos investigar não é o modo como duas experiências diferentes de cristianismo conformaram os procedimentos estéticos em questão e sim a forma como certa exegese cristã é tomada nesses procedimentos como dispositivo poético de vinculação lírica dos corpos a uma experiência crítica de deus. Entendemos que somente a partir de uma compreensão renovada da relação entre corpo, deus e a história poderemos analisar de que modo, através do cristianismo, poesia e crise estão relacionadas na lírica de Camões e nos poemas de Ruy Belo.

\section{DA RESSURREIÇÃO AO JUÍZO: O CRISTIANISMO COMO RELIGIÃO DA CRISE}

Comecemos por uma sugestão de Alain Badiou (2009) em livro dedicado ao apóstolo Paulo. ${ }^{2}$ Para o autor, se existe uma relação propriamente cristã entre sujeito e verdade, a sua constituição histórica passa pela vinculação de um corpo de fiéis a um acontecimento: a ressurreição de 
Cristo. Ainda segundo Badiou, trata-se de um acontecimento-referência cuja localização histórica, ou conteúdo referenciado, importa menos que a fidelidade de um conjunto de viventes à sua existência. Como assinala o filósofo, para os cristãos, o corpo ressurreto de Cristo é antes um horizonte de significação histórica que um objeto representado em tal horizonte. Podemos deduzir dessas proposições um paradoxo: o acontecimento em que se baseia o modo cristão de ler a história está incluso na ordem temporal que ele fundamenta, o que significa dizer que ele aparece simultaneamente como fonte do procedimento de leitura e como evento a ser lido em tal procedimento. Trata-se de uma tautologia em que a história é tomada como desdobramento temporal de um acontecimento, que, em seu percurso, manifesta uma verdade prévia contida na ressurreição, mas sem que esta última necessite de qualquer conteúdo semântico prévio, senão aquele que tal desdobramento manifesta a respeito dela. Isso permite que o corpo de fiéis possa vincular-se à "verdade da ressurreição" sem se ater à contingência histórica em que o vínculo é feito, fundamentando-a em um suposto desígnio de deus manifestado na relação "necessária" da história com esse acontecimento. ${ }^{3}$ Nesse dispositivo, a ressurreição aparece como fundamento último de todos os vínculos, mas sem que ela própria tenha de ser fundamentada em outra coisa que não o gesto de vincular-se a ela. No entanto, aquilo que é recoberto nesse procedimento, a contingência histórica do vínculo, retorna na mortalidade dos fiéis que o assumem. O que o vínculo manifesta, portanto, não é seu fundamento a-histórico, e sim a absoluta historicidade, ou perecibilidade, dos corpos. Perecibilidade que não marca apenas os homens, mas deus, uma vez que o vínculo não pode ser feito de uma vez por todas, mas sim, a cada vez, por novos corpos que o produzem.

Dessa forma, o vínculo acaba por retomar a frágil consistência do gesto que o sustenta, a afirmação sempre frágil de uma verdade supostamente eterna. Daí que, segundo Giorgio Agamben (2014), o processo que levou à ressurreição de Jesus, na perspectiva cristã, seja um momento no qual "a eternidade atravessou a história num ponto decisivo" (AGAMBEN, 2014 , p. 22). Em outras palavras, em que o divino e a história se tocaram em um ponto crítico. Nesse sentido, o cristianismo é uma religião da crise, como atesta Agamben ao analisar a etimologia da palavra:

$\mathrm{O}$ ato de julgar, em grego, se denomina Krisis (de Krino, que etimologicamente significa separar, de-cidir). Ao lado desse significado jurídico, convergem, no termo, tanto um significado médico (Krisis como o momento decisivo na evolução de uma doença, quando o médico deve "julgar" se o paciente morrerá ou sobreviverá) quanto teológico (o Juízo: en emerai Kriseos, "no dia do Juízo", é a advertência que retoma mais vezes na boca de Jesus; em Paulo, en emerai ote crinei “no dia em que Deus Julgará”) (AGAMBEN, 2014, p. 33)

Como afirma o filósofo, a palavra crise não diz respeito somente ao ato jurídico de aplicar a lei, mas também ao ponto decisivo de uma doença, ponto no qual a salvação e a morte estão imbricadas. Para o cris- 
tianismo, esse ponto decisivo aponta de maneira radical para uma zona de indecidibilidade entre o divino e a história. Trata-se aqui de uma decisão pelo indecidível, ou, de maneira mais clara, de optar por se manter em um ponto crítico no qual a história está em crise com seu próprio sentido, uma vez que, nessa perspectiva, não se pode afirmar um sentido último para ela, a não ser a espera indefinida pelo Juízo Final. A espera do juízo, por sua vez, não pode ser outra coisa que não a espera pela crise, ou seja, pelo corte na linha do tempo que irá separar em definitivo a salvação e a morte. No entanto, essa espera já é ela mesma uma precipitação na crise, na medida em que ela lança os homens em um processo sem sentença através do qual toda decisão só pode ser tomada diante do indecidível.

A crise do juízo e o juízo enquanto forma definitiva, mas adiada, da crise estão implicados na formulação cristã do fim último da história. Dito isso, voltemos à questão da ressurreição, pois é no corpo do Cristo que essa implicação se torna ainda mais problemática. Conforme analisa Agamben:

Enquanto Jesus é homem, é homem e basta. Por isso seu testemunho é paradoxal: ele deve dar testemunho neste mundo de que o seu reino não é deste mundo - não que ele seja aqui um simples homem, e, noutro lugar, seja um deus (AGAMBEN, 2014, p. 59)

Nessa perspectiva, o corpo do Cristo realiza aquilo que é impossível para os cristãos: a coincidência entre o divino e o humano neste mundo. Daí que ele também testemunhe essa impossibilidade como vivência interditada a qualquer outro homem que não seja um deus encarnado. De uma forma radical, poderíamos dizer que aquilo que o Cristo realiza é o interdito fundamental do cristianismo: um corpo que seja a imagem e semelhança de deus. Assim, o corpo do Cristo é uma aberração santificada, ou seja, um ponto de indistinção entre o sagrado e o profano que encarna em si a impossibilidade para o homem de ser deus. Esse corpo impossível garante um modelo de justiça para o cristianismo, isto é, um critério de seleção pelo qual seremos julgados: segundo nossa maior ou menor semelhança com esse deus encarnado. Mas, ainda há um segundo elemento nesse processo: o corpo imolado de deus. O corpo inocente que se deixa imolar põe em crise a justiça de todo e qualquer julgamento na mesma medida em que transforma a história em um julgamento infinito da participação do homem na imolação de deus. $\mathrm{O}$ círculo se fecha e o vínculo com a ressurreição se torna o vínculo com esse corpo imolado e com o julgamento final de nossa culpa na imolação.

Porém, esse dispositivo não funcionaria sem um regime de verdade que lhe fosse correlato. Por regime de verdade, entendo, com Michel Foucault (2014), "a relação entre os procedimentos de manifestação do verdadeiro e as formas de implicação do sujeito (operador, testemunha ou objeto de verdade) que a palavra regime define" (FOUCAULT, 2014, p. 316). A pertinência desse conceito - forjado pensador francês em 1980, 
no âmbito do curso "Do governo dos vivos", ministrado no Collège de France -, fica clara, ao lembrarmos que ele está relacionado à investigação empreendida pelo filósofo a respeito das práticas cristãs de condução dos fiéis por meio do batismo, da penitência e da direção de consciência. Segundo o articulista, foi somente a partir dos séculos III e IV da era cristã que tais práticas foram associadas à obrigação para o fiel de dizer a verdade a respeito de seus desejos, atos e pensamentos. Por isso, o sacramento da confissão, instituído nesse período, incluiu a obrigação à verdade de si no aparato eclesial de condução das almas, tornando-se assim o dispositivo que assinala a emergência do regime cristão de subjetivação por meio da verdade de si.

Temos assim um terceiro termo na relação entre sujeito e verdade no cristianismo primitivo: a obrigação à verdade de si. Se voltarmos à proposição de Badiou, poderemos perceber que nesse caso o vínculo à ressurreição a qual os cristãos estão submetidos não trata somente do juízo final, mas principalmente da investigação subjetiva, da inquirição a respeito do pecado. Aqui aparece a segunda ponta do processo de conversão: a confissão inaugura um procedimento ininterrupto de investigação da fraqueza humana como objeto de juízo. Ela demonstra a inevitável falência do vínculo como condição para o juízo de deus.

Podemos ler de pelo menos duas formas essa obrigação de investigar o pecado. Por um lado, ela pode ser um indicativo da falta em relação a deus como condição necessária da subordinação dos homens à correção de consciência levada a cabo pela igreja católica dos primeiros séculos. De outro, ela atesta que é por meio da diferença e não da coincidência consigo mesmo que a subjetividade cristã foi produzida, uma vez que o cristão deveria ser simultaneamente objeto e testemunha da verdade de si: objeto, pois ele se entregava ao escrutínio de suas falhas tendo como horizonte a verdade divina que supostamente as iluminava diante dele, mas também testemunha, na medida em que era por meio dessa investigação que ele encontrava sua participação no juízo de deus - o cristão era réu e testemunha no processo movido contra si mesmo. Até aqui omitimos outra figura importante da análise foucaultiana: o padre. Porém, essa omissão diz respeito a outro aspecto da análise de Foucault que só tocaremos tangencialmente: o problema da obediência. Apesar disso, vejamos como o filósofo francês entende de maneira muito peculiar a forma da obediência no cristianismo primitivo:

O cristão tem a verdade no fundo de si e está atrelado a este profundo segredo, ele está indefinidamente curvado sobre si e indefinidamente forçado a mostrar a outro o tesouro que seu trabalho, seu pensamento, sua atenção, sua consciência, seu discurso não param de emanar. E é assim que ele mostra que a enunciação do discurso de sua própria verdade não é simplesmente uma obrigação essencial. É uma das formas primeiras de nossa obediência. (FOUCAULT, 2014, p. 261) 
A subjetividade cristã, segundo Foucault, é marcada por um processo contínuo de subjetivação que se confunde com uma tarefa: manifestar a verdade de si diante de outro. O exercício de si diante de um sacerdote faz com que cristão esteja sempre produzindo um ponto crítico de si para o outro. É somente através desse ponto que o sacerdote poderá se ajuizar do fiel, ou seja, fazê-lo apreender a si mesmo como um sujeito em crise. Dito de maneira ainda mais contundente, na subjetivação cristã a crise faz emergir um sujeito.

Assim sendo, o que o sujeito deve manifestar na confissão é sua imperfeição, ou melhor, o movimento ininterrupto da imperfeição em direção a deus. O paradoxo está no fato de esse movimento não constituir uma passagem do imperfeito ao perfeito, mas sim uma sondagem infinita do imperfeito diante da perfeição: o cristão não deve contabilizar suas virtudes a fim de se aproximar do divino e sim negar que possa ter virtudes que se sustentem diante da perfeição de deus. É um trabalho do negativo, um modo de produzir a ausência do divino como condição para ser salvo, aquilo que Foucault entendeu como sendo uma "salvação na imperfeição" (FOUCAULT, 2014, p. 263). O círculo, dessa vez, não se fecha: confessar não é uma relação com o fundamento último da história e sim com a ausência de fundamento último para si. Nesse regime de verdade, o juízo final não pode mais ser um horizonte de espera sem ser, ao mesmo tempo, um aprofundamento da distância entre deus e homem.

Esse processo de distanciamento e aproximação entre o homem e deus ganha uma série de problematizações na lírica camoniana e nos poemas de Ruy Belo. Vejamos primeiramente no poeta do século XVI como isso se dá.

\section{A CRISE DO CORPO: CAMÕES E O FIM DO JUÍZO}

O que essa relação entre corpo, verdade e história pode nos dizer de Camões? O século XVI em que ele viveu estava amplamente implicado em crises: crise da igreja católica, crise da aristocracia feudal europeia, crise econômica portuguesa, etc. Seria fácil definir a poesia do vate português como um produto da crise; o difícil é analisá-la enquanto procedimento de confronto com a forma crítica do tempo formulada pelo cristianismo.

Para tratamos desse aspecto do procedimento estético de Camões devemos trabalhar com a semântica do termo crise, aventada por Reinhart Koselleck (2006), a respeito da hermenêutica histórica do século XVI, em seu livro Futuro Passado. Segundo o articulista, duas acepções desse termo foram simultâneas no período: a primeira que o entendia como um dilaceramento progressivo que encaminhava os cristãos para o corte definitivo entre o divino e o mundano no juízo final; a segunda, que o compreendia como um conjunto de sintomas de que a história estaria chegando a um ponto de viragem em que até mesmo o apocalipse deixaria de ser a única e derradeira expectativa. De maneira paradoxal, poderíamos dizer que aquilo que Koselleck aponta é a crise do juízo final enquanto único ponto crítico da história. 
Eis o nosso problema: Camões parece formular a crise do juízo em termos poéticos, ou seja, ele faz da poesia um lugar de experimentação da crise enquanto forma. Os Lusíadas, por exemplo, é inseparável de um processo de formulação do ponto crítico em que os Cantos e a Viagem do Gama arriscam-se na frágil consistência da forma, ou, se quisermos, na forma enquanto acontecimento fragilmente consistente. Essa fragilidade se torna evidente no poema na medida em que transforma a crise do juízo em um trabalho formal com a crise. Em Os Lusíadas, a crise busca constituir-se como um acontecimento formal. ${ }^{5}$ Desse modo, a forma em Camões deixa de ser um mero instrumento de conformação da matéria para se tornar o movimento pelo qual "a matéria simples busca a forma” (CAMÕES, 2005, p. 57).

A lírica camoniana, um de nossos objetos neste artigo, é amplamente perpassada por esse problema. Mas, para os limites desse texto, analisaremos um soneto camoniano em que as questões levantadas até aqui ganham relevo:

Verdade, Amor, Razão, Merecimento

Qualquer alma farão segura e forte,

Porém, Fortuna, Caso, Tempo e Sorte

Têm do confuso mundo o regimento.

Efeitos mil revolve o pensamento,

E não sabe a que causa se reporte;

Mas sabe que o que é mais que vida e morte

Não se alcança de humano entendimento.

Doutos varões darão razões sumidas,

Mas são experiências mais provadas,

E por isso é melhor ter muito visto.

Cousas há que passam sem ser cridas, e cousas cridas há sem ser passadas

Mas o melhor de tudo é crer em Cristo

(CAMÕES, 2005, p. 115)

O problema do juízo retorna aqui amparado pela questão do valor, ou melhor, dos valores: "Verdade, Amor, Razão, Merecimento". Esses valores são identificados como formas seguras em que a alma encontraria uma fortaleza. Mas eles estão submetidos a outra ordem, aquela fundada na “Fortuna, Caso, Tempo e Sorte”. A subordinação da primeira série à segunda demonstra a inversão do lugar da regência, ou seja, do lugar de funcionamento da lei que rege o mundo. A solidez dos valores do primeiro verso não é capaz de formular um regimento para o mundo, o que os subordina à regência daquilo que lhes escapa. Em outras palavras, o soneto começa com a regência do indeterminado (a fortuna) sobre o determinado (a razão).

Éna segunda estrofe que essa lei ganha um estatuto: ela se confunde com a variedade de efeitos sem causa que revolvem o pensamento, ou, de maneira inversa, que o pensamento revolve. Esse estatuto nos mostra que, mesmo quando não encontramos uma lei imutável a reger o mundo, isso 
não significa que não há meios para pensá-lo. Em vista disso, Camões demonstra, desde o primeiro verso, a lógica formal da confusão do mundo, isto é, ele se relaciona com a forma confusa do mundo, antes de tudo, como uma forma.

No entanto, esse empenho formal esbarra com o enigmático terceiro verso da segunda estrofe, "Mas sabe o que é mais que vida e morte", na medida em que ele nos relaciona com aquilo que não está sob a regência de nenhuma lei, o que não está, portanto, no jogo entre mutável e imutável que viemos descrevendo até aqui. Deparamo-nos assim com aquilo que é formalmente impossível, mas que nem por isso está fora da economia formal do poema. Temos, desse modo, um segundo movimento poético: o soneto deixa de ser uma busca, ou perseguição, da lógica do confuso, e passa ser uma formulação da impossibilidade lógica do divino.

A forma daquilo que "não se alcança de humano entendimento", que está além da vida e da morte, nos remete a uma figura que encarna essa impossibilidade: o corpo do Cristo. Para os cristãos, o Cristo é a encarnação da Verdade, do Amor e da Razão que, ao se fazer homem, passou a ser regido pela fortuna humana, mas sem deixar de ser deus. Daí que esse corpo "só de experiências feito" seja o inexperenciável por natureza. O soneto encena o ponto crítico em que o deus encarnado toca a matéria confusa do mundo, em que ele penetra na forma confusa dessa matéria, não para harmonizá-la, mas para realizar nela um movimento aberrante pelo qual uma impossibilidade lógica passa a existir. Não queremos dizer com isso que o soneto representa a encarnação do Cristo e sim que ele formula o mistério da encarnação enquanto elemento constitutivo do mundo.

Nesse poema, a reversão do modo cristão de se relacionar com o corpo do Cristo é notável: o mistério da encarnação não é mais apresentado como um modelo impossível a partir do qual seremos julgados, pois o que se ressalta nesse corpo é a aberração lógica que ele imprime no mundo.

Não se trata aqui, como no sacramento da confissão, de um modo de subjetivação em que, no decorrer do processo, só encontraríamos nosso próprio vazio diante da perfeição de deus, tampouco da espera por um juízo que supostamente iria concertar as almas: o desconcerto do mundo, a confusão formal dele, é o modo pelo qual o corpo de deus emerge enquanto forma desconcertada da relação entre o divino e o humano.

Para Camões, melhor do que crer, seja em uma razão final para história, seja em que na ausência desta só nos resta vasculhar a profundidade infinita de nossa subjetividade, é crer em Cristo, enquanto dimensão aberrante do mundo, ponto crítico em que o indecidível não faz juízo.

\section{O DIA SEM DEUS: RUY BELO E TRANSUBSTANCIAÇÃO DO SAGRADO}

Se, como analisamos anteriormente, um dos aspectos significativos da lírica de Camões é o modo como ela se vincula, de forma crítica, ao corpo aberrante do Cristo, então o segundo movimento deste ensaio 
consistirá em uma análise da maneira pela qual a poesia de Ruy Belo soube se relacionar com essa dimensão da lírica camoniana.

Desde seu primeiro livro, Aquele grande rio Eufrates, ${ }^{6}$ o viés trágico do deus encarnado comparece na poesia de Ruy Belo junto a uma investigação cerrada da impotência da palavra poética para dizer a morte, ou, de maneira ainda mais drástica, da poesia enquanto modo de dizer essa impotência. Em poemas como "Para dedicação de um homem" e "Teoria da presença de Deus", por exemplo, deus está embrenhado em nossa relação cotidiana com a morte. É diante desse olhar que nos observa morrer, dessa presença que nos transforma em seres terríveis - "Terrível é o homem em quem o senhor/ desmaiou o olhar furtivo das searas" (BELO, 2009 , p. 28) - que a impotência do dizer se torna um estado crítico da palavra. Não por acaso, o poema "Teoria da presença de Deus" começa com o verso "Somos seres olhados" (BELO, 2009, p. 28). Nesse poema, deus se apresenta como testemunha da perda cotidiana de nossos gestos. Por isso, nele deus se constitui como um esforço de dizer a morte sob o ponto de vista daquele que não pode morrer, ou melhor, daquele para quem a morte nunca é definitiva.

Porém, até mesmo a relação com deus de que falamos acima não foi experimentada sem crise por Ruy Belo. Como se sabe, em 1973, o poeta reuniu 27 poemas dos três últimos livros que ele havia publicado até aquele ano (Boca Bilíngue, Homem de Palavras e Transporte do tempo), os reescreveu em parte (com supressão de versos de conteúdo explicitamente religioso e substituição das maiúsculas pelas minúsculas na grafia da palavra deus, por exemplo) e os publicou, com o acréscimo de um poema inédito, sob o sugestivo nome País Possível. Nessa coletânea não constam poemas de seus dois primeiros livros (Aquele grande rio Eufrates e O problema da habitação - alguns aspectos) em que o conteúdo religioso da sua poesia seria supostamente mais marcado.

Todavia, mesmo neste momento, a aproximação com o deus cristão não é negada, ela simplesmente se desvincula de traços excessivamente religiosos e passa a operar como um dos elementos da tradição poética portuguesa que Ruy Belo mobiliza. No entanto, não poderemos tratar da questão do deus encarnado sem primeiro analisarmos como esse fazer poético se posiciona em relação à tradição.

Um exemplo do modo singular de como Ruy Belo se relaciona com a tradição está no título escolhido por ele para a coletânea anteriormente citada: País possível. O livro, publicado um ano após o quarto centenário de publicação de Os Lusíadas (amplamente comemorada pela ditadura salazarista) nos remete a uma elisão feita no poema de Camões: o título que o poeta do século XVI escolheu para sua epopeia não é "Os portugueses” e sim Os Lusíadas, assim como o título de Ruy Belo não é Portugal possível, mas país possível. No poema épico camoniano, a denominação Os Lusíadas joga com a possibilidade de fracasso na viagem marítima 
de Vasco da Gama: Os Lusíadas são os filhos de Luso, netos de Baco, o deus que sabota constantemente a viagem mercante. $\mathrm{O}$ que significa dizermos que os supostos heróis dessa epopeia são consanguineamente vinculados ao próprio fracasso, que se apresenta a eles na figura do deus do Vinho. Desse modo, se Ruy Belo recupera a elisão camoniana, o país possível de que ele trata não é uma utopia não realizada e sim uma diç̧ão poética que aposta na possibilidade do fracasso. O poeta não perde de vista essa possibilidade enquanto elemento constitutivo tanto do poema épico camoniano, quanto da formulação de país nele inscrita.

Dito isso, devemos deixar claro que esse desvio em direção à epopeia não é gratuito, ele nos dará condição de entendermos um elemento crucial para análise da relação da poesia de Ruy Belo com um aspecto cristão da lírica camoniana, a saber, a derrota do corpo enquanto procedimento poético que vincula deus e morte a um estado crítico da palavra.

Para tratarmos dessa questão, recorreremos à análise de um poema do livro País possível, publicado originalmente no livro Homem de palavra[s], mas que é exemplar, nesta coletânea, do país possível que Ruy Belo formula a partir de Camões.

\section{CORPO DE DEUS}

A minha unha tem crescido tanto

e entretanto vim morrendo pouco a pouco

temi amei preocupei-me com problemas

fui feliz vivi a vida emocionei-me

Venceram-se diversas prestações

A minha poesia é por vezes mínima e mesquinha

Aqui estou eu perdido na contemplação da unha

A unha pequenina a que regresso sempre

Não canto armas nem barões nem mesmo este mar

que desdobradamente aqui vem rebentar

em ondas de água azul em algas e pedrinhas

Afinal tão instrutivo é

perder-me na contemplação do pé

descalço aqui à doce beira-mar

como aprofundar os mistérios deste dia

em que Cristo instituiu a eucaristia

E eu comecei o dia à procura de livros

preocupado com contas a pagar

sem bem saber de mim nem do que é meu

(Falo muito de mim e de várias maneiras

algumas delas transpostas fantásticas fingidas

mas quem há-de morrer e quem é que nasceu

mais presente a mim próprio do que eu?)

Havia porventura de me recordar

da ceia do senhor do pão do vinho?

O meu pão é todo deste deste dia

E vou buscá-lo em contemplação da unha:

crescem mais as dos pés do que as das mãos

Serei eu que as corto menos vezes? 
Será e terá sido sempre assim com toda a gente?

Cristo terá alguma vez sabido isso?

Doer-lhe-ia o pé ao instituir a eucaristia?

Mas o meu pão é todo deste dia

e doem-me muito mais os meus dois pés

do que o corpo de Cristo embora meu amigo

Sermões e procissões interpretações doutrinais

talvez mundo perdido para nunca mais

aqui junto do mar junto dos meus

mesmo ao falar de deus eu me esqueço de deus

(BELO, 2009, p. 517)

O poema se chama "Corpo de Deus", no entanto, nos primeiros versos só o que constatamos é um sujeito a observar o crescer das unhas. As células mortas que compõem a unha, a morrer pouco a pouco, dão a ele certa dimensão da morte. Enquanto elas crescem, ele observa a si mesmo morrendo. Junto a esse crescer também passa a vida, cheia daquilo que morre, como uma unha. Em outro segmento do poema, a poesia se confunde com essa contemplação mínima e mesquinha do corpo, ou melhor, da parte do corpo que morre enquanto cresce. A partir daqui o poema ensaia um segundo movimento e a epopeia camoniana é citada: "Não canto armas nem barões nem mesmo este mar/ que desdobradamente aqui vem rebentar". Recordemos os quatro primeiros versos de Os Lusíadas "As armas e os barões assinalados/ Que da Ocidental Praia Lusitana/ Por mares nunca dantes Navegados/ Passaram muito além da Taprobana" (CAMÕES, 1978, p. 25). O que se celebra na abertura deste poema são os feitos destes homens que se lançaram ao mar; já no poema de Ruy Belo, parte-se do ponto de vista do homem que fica na praia, ocupado na contemplação do seu pé, para rechaçar o canto dos grandes feitos, e, por meio deles, também a ideia do mar como um mistério que desafia o engenho humano. Se o mar aparece aqui, é somente na medida em que ele se relaciona com a contemplação das ruínas do corpo: ele próprio é uma presença arruinada, ou melhor, rebentada entre algas e pedrinhas.

Toda essa contemplação de ruínas corpóreas, em que até o mar é um corpo arruinado, compõe outro mistério, que não aquele celebrado no Canto I: "Afinal tão instrutivo é/ perder-me na contemplação do pé/ descalço aqui à doce beira-mar/ como aprofundar os mistérios desse dia/ em que Cristo instituiu a eucaristia”. A eucaristia, como se sabe, é inseparável da transubstanciação, isto é, da transformação do pão e do vinho no corpo e sangue do Cristo. Essa transformação, por sua vez, é considerada pelos católicos como um mistério da fé, ou se quisermos, como um impossível lógico que a fé dos cristãos faz existir. Ela acontece durante a missa, como um ritual que repete o gesto do Cristo na santa ceia. O poema de Ruy Belo desloca esse gesto do ritual a qual ele pertence e o faz funcionar no interior de outra transubstanciação, aquela que transforma o sagrado em uma relação cotidiana com a morte. 
Nesses versos, o misterioso corpo do Cristo é tão possível no mundo quanto uma unha, ou um dia qualquer que se perca na praia. Não há nenhum privilégio ontológico entre qualquer dos dias de nossa vida e aquele em que o Cristo institui a eucaristia, mas isso não significa diminuir o mistério da eucaristia e sim espraiá-lo na experiência cotidiana do corpo. Ruy Belo nos lembra de que o Cristo foi corpo antes de ser um ritual de transubstanciação.

Porém, é somente ao afinal do poema que o espraiamento do mistério redimensiona o sentido do possível. Após uma série de questionamento sobre o corpo do Cristo (se lhe doíam os pés quando instituiu a eucaristia, se ele sabia o motivo de crescerem mais as unhas do pé do que as das mãos), a voz lírica no poema nos diz que lhe doí muito mais os pés do que o corpo de Cristo. Talvez vejamos aqui o ponto crucial da relação dos cristãos com corpo do deus encarnado. Isso porque a nenhum deles é dado o direito de se relacionar com o Cristo como um homem comum, isto é, como homem que supostamente sofreu das mesmas inquietações cotidianas que nós. No entanto, a extrema dor do deus imolado é sempre trazida à tona como modo de sentenciar o corpo dos cristãos a uma ascese, uma vez que diante daquela dor todo prazer seria condenável. Ruy Belo se nega a sentir mais a dor do Cristo que sua própria dor, optando por se relacionar com ele enquanto homem cotidiano.

Desse modo, se em Camões o corpo do deus encarnado era uma impossibilidade lógica que o poema apreendia enquanto forma do mistério, em Ruy Belo o mistério não é a encarnação, mas a possibilidade de deus ser um homem comum. O que o poeta celebra é a extraordinária possibilidade daquilo que é comum. Daí que, ao falar de deus, o poema se esqueça de deus. O corpo de deus é o país possível em que o sagrado se confunde com a experiência diária de nossos corpos.

\section{REFERÊNCIAS BIBLIOGRÁFICAS}

AGAMBEN, Giorgio. Pilatos e Jesus. Trad. Silvana de Gaspari e Patrícia Peterle. São Paulo: Boitempo,2014.

. O reino e a Glória. Trad. de Selvino J. Assman.São Paulo: Boitempo, 2007.

BADIOU, Alain. São Paulo: a fundação do universalismo. Trad. Wanda Brant. São Paulo: Boitempo, 2009.

BELO, Ruy. Todos os poemas. 3. ed. Lisboa: Assírio \& Alvim, 2009.

CAMÕES, Luís de. Rimas. Texto estabelecido e prefaciado por Álvaro José da Costa Pimpão. Coimbra: Almedina, 2005.

. Os Lusíadas. Edição organizada por Emanuel Paulo Ramos.

Porto: Porto Editora, 1978. 
FOUCAULT, Michel de. Do governo dos vivos. Trad. Eduardo Brandão. Edição estabelecida sob a coordenação de Michel Senellart. São Paulo: Martins Fontes, 2014.

KOSELLECK, Reinhart. Futuro Passado: Contribuição à semântica dos tempos históricos. Trad. Wilma Patrícia Maas, Carlos Almeida Pereira César. Rio de Janeiro: Contraponto; Ed. PUC-Rio, 2006.

MAFFEI, Luis. Despejo Quieto. Rio de Janeiro: Eduff, 2015.

SILVEIRA, Jorge Fernandes da. O Tejo é um rio controverso. Rio de Janeiro: 7 Letras, 2008.

Recebido para publicação em 30/11/2016

Aprovado em 20/03/2017

\section{NOTAS}

1 Graduado em Letras Língua Portuguesa pela Universidade Federal do Amazonas (UFAM). Mestre em estudos de literatura (subárea teoria da literatura e literatura brasileira) pela Universidade Federal Fluminense (UFF), doutorando do programa de literatura comparada da mesma universidade com bolsa da Fundação de amparo à pesquisa do estado do Amazonas ( FAPEAM).

2 BADIOU, Alain. São Paulo: a fundação do universalismo. Trad. Wanda Brant. São Paulo: Boitempo, 2009.

3 A esse respeito ver : AGAMBEN, Giorgio. O reino e a Glória. Trad. Selvino J. Assman. São Paulo: Boitempo, 2007.

$4 \mathrm{O}$ curso foi transcrito e publicado com o mesmo nome por Michel Sennelart.

5 Servirmo-nos aqui da tese segundo a qual a escrita de Os Lusíadas é marcada por um "Se" condicional que confronta o poema inúmeras vezes com a possibilidade de não se realizar. A tese é melhor explorada por Luis Maffei (2014) e Jorge Fernandes da Silveira (2008) em seus respectivos livros: Despejo Quieto e O tejo é um rio controverso

6 Todas as citações da obra de Ruy Belo, presentes neste ensaio, tiveram como referência a edição das obras completas publicada pela Assírio \& Alvim, que consta nas referências bibliográficas. 